\title{
Iran's shift in family planning policies: concerns and challenges
}

\author{
Mohammad Karamouzian ${ }^{1,3}$, Hamid Sharifi ${ }^{2}$, Ali Akbar Haghdoost ${ }^{3, *}$ \\ Abstract \\ Iran's significant success in implementing Family Planning (FP) during the past 25 years, has made it a role \\ model in the world. The Total Fertility Rate (TFR) in Iran has dropped from 6.5 in 1960 to 1.6 in 2012, which \\ is well below the targeted value of 2.2 for the country. Iran's success story, however, did not merely root in \\ the implementation of FP programs. In other words, families' strong tendency to limit fertility and delayed \\ marriages had an undeniable role in decreasing the TFR. On the other hand, Iranian policy-makers are very \\ concerned about such a decrease and have recently restricted access to contraception, while outlawing any \\ surgery that reduces fertility. This paper, tries to highlight the pros and cons of such restrictive policies, and \\ argue that the policy-makers might be jeopardizing the success of Iran's FP program by overestimating its role \\ in the TFR reduction rate. \\ Keywords: Family Planning (FP), Total Fertility Rate (TFR), Health Policy, Population Control, Iran \\ Copyright: @ 2014 by Kerman University of Medical Sciences \\ Citation: Karamouzian M, Sharifi H, Haghdoost AA. Iran's shift in family planning policies; concerns and \\ challenges. Int J Health Policy Manag 2014; 3: 231-233. doi: 10.15171/ijhpm.2014.81
}

Article History:

Received: 14 June 2014

Accepted: 31 August 2014

ePublished: 2 September 2014

${ }^{*}$ Correspondence to

Ali Akbar Haghdoost

Email: ahaghdoost@kmu.ac.ir
$\mathrm{I}$ ran's Family Planning (FP) program's commencement goes back to early 70s, where banners saying "Two children are enough" appeared in every public health sector across the country. These policies were then suspended due to the political climate after the 1979 Islamic revolution, when most policies attributed to the royal family were considered western and inappropriate. FP programs were then reversed, and the newly established government started promoting large family sizes, by providing socio-economic benefits for larger families. Soon after the country was imposed by an unwanted war against Iraq, these policies were followed to an even greater extent, as a large population could be considered an advantage.

During the final years of the war, expert advocacies highlighted the importance of reintroducing FP policies to the health system to help fix the weakened and damaged post-war economy (1). A major drive for this reintroduction, was the fatwa (a religious statement by a highly ranked clergy man) issued by Imam Khomeini-the former supreme leader of Iran-and other top-ranking clerics, stating that "contraception was not inconsistent with Islamic tenets, as long as it did not jeopardize the health of the couple, and was used with the informed consent of the husband" (2). In the next two decades, Iran managed to take a leap forward in reducing its population, by promoting free contraceptives as well as free or inexpensive vasectomies (1); however, this success did not merely root in the FP programs, and was also driven by families' strong tendency to limit fertility-mainly through natural contraceptive methods (i.e. withdrawal) — and delayed marriages (3-6). Overall, the government did a really fine job and Iran's recent demographic change, is often outlined as a success story of implementation of FP programs.

The Total Fertility Rate (TFR) in Iran, has declined from 6.5 in 1976 to 1.6 births per woman in 2012 (3). One of the features that made Iran's experience unique, was the decline in TFR in rural areas (along with cities), from an estimate of 8.1 in 1976 to 2.4 births per woman in $2000(7,8)$. Nonetheless, it was the speed and level of decline in the TFR that surpassed everyone's expectations; a target set to be met by 2011, was already met by 2000. In other words, while Iran's first official target was set to reduce the TFR to 4.0 births per woman by 2011 , the rate was already down to 2.0 by 2000 (7). Significant decreased level of childbearing as well as increased maternal and child health, have made the country a role model around the globe (9), and the Minister of Health-Alireza Marandiwas awarded by the World Health Organization (WHO) in 2001, for Iran's effective and successful FP programs under his supervision (10).

Recent policy changes regarding Family Planning in Iran Despite its successful experience, Iran's approach to FP policies has changed during the past two years. It was the former president-Mahmoud Ahmadinejad-who first highlighted the need for increasing the country's population, stating that Iran could support a population of up to 150 million people. He further declared that the "Two children are enough" motto, stemmed from a wrong imported western perspective $(11,12)$. Shortly after, the supreme leader of Iran-Ayatollah Seyed Ali Khamenei-also pointed out his opinion about the population control strategies. While expressing his concerns about the potentials of the youth population throughout the country, he stated that FP control policies should have been 
ceased in the late 90s. He also declared his worries about the current situation which could lead to a TFR below the replacement level.

Consequently, serious debates over the necessity of continuing the FP programs were initiated among policy-makers and scientists. Policy-makers were leaning towards a rapid shift in the FP strategies, by restricting access to contraceptive use and birth limiting surgeries. Eventually, in July 2012, the former minister of health-Marzieh Vahideh Dastjerdi-officially stated that the FP budget was cut to a great extent, and the Ministry of Health and Medical Education (MoHME) was no longer able to provide all the routine public FP services, through the public health sector. While the new motto is "at least two children is ideal", the MoHME is currently trying to encourage women to have three children by the age of 30. At present, public access to free contraceptives is not banned; however, it is restricted to a great extent. Moreover, Iran's parliament has recently outlawed vasectomies and tubectomies, except to save a person's life. Based on this legislation, any medical practitioners found engaging in any surgery that reduces fertility, could face up to five years of imprisonment.

\section{Why should we care?}

Population control policies are multifaceted policies, and various aspects of their implementation are of outmost importance. While acknowledging the policy-makers' concern about overshooting the targeted TFR, the possible adverse effects of such untargeted restrictive policies on FP, as well as their effectiveness in reaching their primary goal of increasing the population and the desired 2.2 TFR in the long run, should not be overlooked.

It seems that the role of contraception in decreasing the population in Iran, has been overestimated by policy-makers. Recent findings indicate that the fertility rate in Iran, began to decline in 1985; four years before the introduction of new FP policies in 1989 (13). Moreover, studies suggest that only 61\% of the reduction in TFR could be attributed to FP practices, and rest has been mainly due to the elevated age of marriage among Iranian women (primarily due to their pursuit of higher educations and the shift in some of the socio-cultural norms), desire to have no future birth, and other proximate determinants of reduction in fertility (4-6). Recent studies have also reported that withdrawal practice, is much greater among birth limiters; another evidence that indicates the limited effectiveness of broad restrictions in accessing contraception to increase the TFR $(6,14)$.

An existing example of ineffectiveness of restricting FP access in order to increase the population, could be Romania. A law issued in 1966 in Romania, criminalized abortion and banned modern contraceptive use, unless for very limited medical conditions (15). Although the fertility rate began to rise at first, the TFR finally stabilized at 2.3 births per woman in late 80 s. Another point of concern, would be the possible adverse effects of such rapid policy shifts on illegal unplanned pregnancies and abortions (usually self-induced or performed by unprofessional individuals), due to limited access to contraceptives. In Romania, absence of contraceptives led to a surge in illegal abortions and as announced later, Romania had the highest maternal mortality rate (most of which were abortion-related) in Europe during the 80s $(15,16)$. Although Romania could be considered as an extreme example of the unwanted effects of such restrictive policies, and Iran's case could be very different (as contraceptives are not totally banned and could still be accessed through the private sector at a higher expense), the possible adverse effects of restricting the FP services as well as criminalizing birth limiting surgeries should be further emphasized.

Iran needs a comprehensive purposive population control policy, which takes the needs of all socio-economic levels into account. Those who would suffer the most in Iran, are most likely the lower-income families. Accordingly, this could lead to an increase in the socio-economic gap between the privileged and the impoverished in the long run. Vulnerable women (including female sex workers and female intravenous drug users), who rely mostly on public services with regards to contraceptives and FP services, are another important group of population whose needs should be taken into account (17-19). Restricting the access of such important populations to contraception, could render tons of money and years of effort spent on promoting safe sex and reducing sexually transmitted infections (including HIV), utterly useless (20).

All in all, it seems policy-makers are jeopardizing the success of Iran's FP program, by overestimating its role in the TFR reduction rate. However, the existing need for continuous support of purposive FP programs should not be ignored. Today families, are more concerned about the future of their children than before, and the generational shifts towards higher education, occupation and income are much more prominent than before; determinants that have a direct impact on limiting or spacing birth (21-23). Policy-makers have been promoting smaller family size for over two decades and have shifted public beliefs accordingly, hence, questioning all those policies and changing the population control policies over a short period is very unlikely to meet a high acceptability among people. Shifting population policies without proper supervision and a timely agenda, could effectively roll back decades of efforts to strengthen Iran's economy through maintaining population growth at an ideal level. Iran, is still struggling with providing occupation and housing for the baby boom generation of the 80 s.

As outlined earlier, several examples demonstrate how a single desire for increasing family size, may not necessarily be fulfilled through broad and untargeted restriction of access to contraception. These hasty policies, are more likely to affect the family size of the poor and low-income families, which would affect their quality of life in the upcoming years. Iran needs to come up with a new comprehensive and multi-level program to increase the TFR to its optimum level of 2.2. At the same time, policy-makers should address specific important issues such as people's quality of life, possible surge in illegal abortions and unwanted pregnancies, risk reduction of HIV/ STIs, and service delivery to immigrants as well as marginalized and vulnerable populations. These programs should also try to harmonize the efforts in targeting the proposed desired 
population (150 million), with the differences among people living in different geographical zones. As a final point, concurrent assessment of the effectiveness of these new population control policies, by using different scientific indicators in different subpopulations and different socioeconomics, is essential.

\section{Ethical issues}

No ethical issues are raised.

\section{Competing interests}

The authors declare that they have no competing interests.

\section{Authors' contributions}

All authors contributed equally to the conceptualization of the paper. MK drafted the manuscript and all authors reviewed and approved the final version.

\section{Authors' affiliations}

${ }^{1}$ School of Population and Public Health, Faculty of Medicine, University of British Columbia, Vancouver, BC, Canada. ${ }^{2}$ Research Center for Modeling in Health, Institute for Futures Studies in Health, Kerman University of Medical Sciences, Kerman, Iran. ${ }^{3}$ Regional Knowledge Hub, and WHO Collaborating Center for HIV Surveillance, Institute for Futures Studies in Health, Kerman University of Medical Sciences, Kerman, Iran.

\section{References}

1. Hoodfar $\mathrm{H}$, Assadpour $\mathrm{S}$. The politics of population policy in the Islamic Republic of Iran. Stud Fam Plann 2000; 31: 19-34. doi: 10.1111/j.1728-4465.2000.00019.x

2. Mehryar AH. Ideological basis of fertility changes in postrevolutionary Iran: Shiite teachings vs. pragmatic considerations. Tehran: Institute for Research on Planning and Development; 2000.

3. Erfani A. Fertility in Tehran City and Iran: Rates, Trends and Differentials. Population Studies 2013; 1: 87-107.

4. Erfani A, McQuillan K. Rapid fertility decline in Iran: analysis of intermediate variables. J Biosoc Sci 2008; 40: 459-78. doi: $10.1017 / \mathrm{s} 002193200700243 x$

5. Erfani A. A reversal in the population policy of Iran: Do curbing family planning programs raise low fertility? The XXVII IUSSP International Population Conference; 2013; Busan, Republic of Korea.

6. Erfani A, Ilknur Yuksel-Kaptanoglu. The use of withdrawal among birth limiters in Iran and Turkey. Stud Fam Plann 2012; 43: 21-32. doi: 10.1111/j.1728-4465.2012.00299.x

7. Statistical Center of Iran. Iran statistical yearbook 2001. Tehran: Islamic Republic of Iran, Management \& Planning Organization, Statistical Center of Iran; 2001. p. 786.

8. Roudi-Fahimi F, Gupta Y, Swain P, Ram F, Singh A, Agrawal P, et al. Irans family planning program: responding to a nations needs. J Popul Res (Canberra) 2002; 19: 1-24.

9. Vahidnia F. Case study: fertility decline in Iran. Popul Environ
2007; 28: 259-66. doi: 10.1007/s11111-007-0050-9

10. Roudi-Fahimi F. Iran's family planning program: responding to a nation's needs. Washington DC: Population Reference Bureau; 2002.

11. Amuzegar J. Ahmadinejad's Legacy. Middle East Policy 2013; 20: 124-32. doi: 10.1111/mepo.12051

12. Henry F. President Ahmadinejad's Speech At UN. update 2013, 328.

13. Erfani A, McQuillan K. The changing timing of births in Iran: an explanation of the rise and fall in fertility after the 1979 Islamic Revolution. Biodemography Soc Biol 2014; 60: 67-86. doi: 10.1080/19485565.2014.899428

14. Erfani A. Factors associated with the use of withdrawal in Iran: Do fertility intentions matter? Journal of Comparative Family Studies 2012; 43: 301-12.

15. Serbanescu F, Morris L, Stupp P, Stanescu A. The impact of recent policy changes on fertility, abortion, and contraceptive use in Romania. Stud Fam Plann 1995; 26: 76-87. doi: $10.2307 / 2137933$

16. Constantin A, Neagu C, Bucur A, Marinescu B. Eight years of experience in the first Romanian center of family planning and contraception. Eight years of experience in the first Romanian center of family planning and contraception 1999; 4: 57-60. doi: 10.3109/13625189909064005

17. Karamouzian M, Haghdoost AA, Sharifi H. Addressing the needs of sexual partners of people who inject drugs through peer prevention programs in Iran. Int J Health Policy Manag 2014; 2 : 81. doi: 10.15171/ijhpm.2014.19

18. Khajehkazemi R, Osooli M, Sajadi L, Karamouzian M, Sedaghat A, Fahimfar N, et al. HIV prevalence and risk behaviours among people who inject drugs in Iran: the 2010 National Surveillance Survey. Sex Transm Infect 2013; 89: iii29-32. doi: 10.1136/ sextrans-2013-051204

19. Alipour A, Haghdoost AA, Sajadi L, Zolala F. HIV prevalence and related risk behaviours among female partners of male injecting drugs users in Iran: results of a bio-behavioural survey, 2010. Sex Transm Infect 2013; 89: iii41-4. doi: 10.1136/ sextrans-2013-051201

20. Karamouzian M, Nasirian M, Sedaghat A, Haghdoost AA. HIV in Iran. Lancet 2014; 383: 1958. doi: 10.1016/S01406736(13)62645-8

21. Erfani A. The Impact of Family Planning on Women's Educational Advancement in Tehran, Iran [internet]. 2012. Available from: http://www.icrw.org/files/publications/Erfani\%20MS\%20edit\%20 Feb\%202013.pdf

22. Karamouzian M, Shokoohi M. Sexual and Reproductive Health Education in Iranian Schools. The J Adolesc Health 2014; 55 : 149-50. doi: 10.1016/j.jadohealth.2014.04.009

23. Roudi-Fahimi F, Moghadam VM. Empowering women, developing society: Female education in the Middle East and North Africa. Washington, DC: Population Reference Bureau; 2003. 